\title{
Muhasebe ve Denetim Bölümü Öğrencilerinin Profili ve Muhasebe Mesleğine Bakışları: Bilecik Şeyh Edebali Üniversitesi, Uygulamalı Bilimler Yüksekokulu Örneği
}

\author{
Berna DEMIR ${ }^{1}$ \& Melike ÖZTÜRK ${ }^{2}$ \& Ayşenur ATALAY $Y^{3}$
}

\begin{abstract}
$\ddot{O} \mathbf{z}$
Bu çalışma, Uygulamalı Bilimler Yüksekokulu, Muhasebe ve Denetim Bölümü'nde öğrenim gören öğrencilerin, profilini ve muhasebe mesleğine bakışlarını ortaya koymak amacıyla yapılmıştır. Çalışma kapsamında, bölümde öğrenim gören öğrencilere anket uygulanmıştır. Yapılan çalışma sonucunda kadın öğrencilerin erkek öğrencilerden sayıca fazla olduğu görülmüştür. Bu bölüm, üniversite tercih sıralamasında öğrencilerin büyük çoğunluğunun ilk 5 tercihi içinde yer almaktadır. Üniversite sınavında alınan puan bu bölümü tercih etmelerinde etkili olmuştur. Öğrencilerin çoğu, bu bölümü kendi isteğiyle seçmiştir. Muhasebe mesleğinin içe dönük (asosyal) bir meslek olmadığını düşünmektedirler. Öğrencilerin büyük çoğunluğu muhasebe mesleğinde etik kurallara uyulması gerektiğini düşünmesine rağmen muhasebede mükellefin değil toplumun çıkarlarının önemli olduğınu düşünen öğrencilerin sayısı daha azdır. Mali müşavirlik mesleğinin kadınlara uygun bir meslek olduğunu düşünmektedirler. Kamu sektöründe çalışmak isteyenlerin sayısı daha fazladır. Öğrenciler öncelikle mali müşavir olmak ve işletmelerin muhasebe departmanında çalışmak istemektedirler.
\end{abstract}

Anahtar Kelimeler: Uygulamalı Bilimler Yüksekokulu, Muhasebe ve Denetim Bölümü, öğrenci profili, muhasebe mesleği

The Profiles Of The Students Of Accounting And Auditing Programme And Their Views On The Accounting Profession: Bilecik Şeyh Edebali Unıversity, School Of Applied Sciences Sample

\begin{abstract}
This study was carried out to reveal the profile of the students studying in the Accounting and Auditing Programme of the School of Applied Sciences and their views on the accounting profession. Within the scope of the study, a questionnaire was applied to the students studying in the programme. As a result of the study, it was observed that female students were more than male students. This section is among the top 5 preferences of the majority of students in the university preference ranking. The score of the university exam was effective in choosing this programme. Most of the students chose this programme voluntarily. They think that the accounting profession is not an asocial profession. Although the majority of students think that ethical rules must be obeyed in the accounting profession, the number of students who think that the interests of the society are not important but the taxpayers are less. They think that the profession of financial consultancy is a suitable profession for women. The number of people who want to work in the public sector is higher. Students primarily want to be a financial advisor and work in the accounting departments of enterprises.
\end{abstract}

Keywords: School of Applied Sciences, Accounting and Auditing Programme, student profile, accounting profession

\footnotetext{
1 Doç. Dr., Bilecik Şeyh Edebali Üniversitesi, Uygulamalı Bilimler Yüksekokulu, Muhasebe ve Denetim Bölümü, berna.demir@bilecik.edu.tr

$\frac{2}{2}$ Tezli Yüksek Lisans Öğrencisi, Bilecik Şeyh Edebali Üniversitesi, Sosyal Bilimler Enstitüsü, Uygulamalı Bilimler Yüksekokulu, Muhasebe ve Denetim Bölümü, melikeoztturk@gmail.com

${ }^{3}$ Tezli Yüksek Lisans Öğrencisi, Bilecik Şeyh Edebali Üniversitesi, Sosyal Bilimler Enstitüsü, Muhasebe ve Denetimi Bölümü, aysenurratalay@gmail.com
} 


\section{Giriş}

Muhasebe, işletmelerde meydana gelen mali nitelikteki işlemleri kaydeden, sınıflandıran, özetleyen, analiz eden, yorumlayan ve elde edilen tablo ve raporları ilgili kişi ve kurumlara ileten bir bilgi sistemidir. Muhasebede üretilen bilgiler, işletme ile ilgili planların yapılması ve kararların alınmasında önemlidir. Bu nedenle üretilen bilgilerin doğruluk ve güvenilirliğinin sağlanmasında denetimin rolü büyüktür.

Son yıllarda uluslararası muhasebe ve finansal raporlama standartları ile uluslararası denetim standartlarının benimsenmesindeki artış doğrultusunda muhasebe dünyasında yaşanan gelişmeler; iş dünyasının muhasebe meslek mensuplarından beklentilerini değiştirmektedir. Ülkemizde yürürlüğe giren 6102 sayılı Türk Ticaret Kanunu ile söz konusu gelişmeler hızla yaşanmakta; vergi muhasebesi odaklı muhasebe anlayışı yerini doğru ve güvenilir finansal raporlama ve denetim odaklı muhasebe anlayışına bırakmaktadır. Bu gelişmeler çerçevesinde muhasebecilik mesleği çok daha farklı bir konuma gelmekte; muhasebecilerin sahip olması gereken bilgi ve beceri yelpazesi genişlemektedir. Ülkemizde verilen muhasebe eğitiminin bu bilgi ve becerileri sağlayacak nitelikte olması gerektiği kaçınılmazdır (Poroy vd. 2014: 122).

$\mathrm{Bu}$ gereksinim doğrultusunda Uygulamalı Bilimler Yüksekokulları bünyesinde kurulan Muhasebe ve Denetim Bölümleri'nin amacı muhasebe mesleğinde kariyer yapmak isteyen öğrencilerin müşavirlik, denetim ve maliyet muhasebesi alanlarında hem teorik açıdan, hem de uygulama açısından gerekli alt yapıyla donatılarak, hali hazırda yaşanan eğitim sonrası mesleğe uyum sorunlarını yaşamadan, iş hayatına atılmalarını ve sektörün talebinin karşılanmasını sağlamaktır (Kurnaz ve Gümüş, 2010: 157).

Bilecik Şeyh Edebali Üniversitesi, Uygulamalı Bilimler Yüksekokulu, Muhasebe ve Denetim Bölümü de lisans seviyesinde öğrenim vererek yetişmiş insan gücünün karşılanmasında etkili olmaktadır. Bölümün amacı muhasebe ve denetim alanında uzman kişilerin yetişmesine katkı sağlamaktır. Bu öneminden dolayı Uygulamalı Bilimler Yüksekokulu, Muhasebe ve Denetim Bölümü ögrencilerinin profilini ve muhasebe mesleğine bakışlarını ortaya koymak amacıyla bu çalışma yapılmıştır.

\section{ARAŞTIRMANIN AMACI VE ÖNEMI}

$\mathrm{Bu}$ çalışmanın amacı, geleceğin muhasebe meslek mensubu olacak, Bilecik Şeyh Edebali Üniversitesi, Uygulamalı Bilimler Yüksekokulu, Muhasebe ve Denetim Bölümü öğrencilerinin profilini ve mesleğe bakışlarını ortaya koymaktır. Bu araştırmada sorgulanan ana unsurlar aşağıda verilmiştir.

Öğrencilerin;

- Cinsiyete göre dağılımı, 
- Sınıflara göre dağılımı,

- İkamet ettikleri bölgelere göre dağılımı,

- Mezun oldukları liseye göre dağılımı,

- Muhasebe ve Denetim Bölümü’nü tercih etme sıraları

- Muhasebe ve Denetim Bölümü'nü seçme sebepleri

- Muhasebe mesleği hakkındaki düşünceleri,

- Mali müşavirlik mesleğinin kadınlara uygun bir meslek olmadığını düşünenlerin cinsiyete göre dağılımı,

- Çalışmak istedikleri sektör,

- Kariyer planlar1.

\section{Araştırma Yöntemi}

Araştırmanın evrenini Bilecik Şeyh Edebali Üniversitesi, Uygulamalı Bilimler Yüksekokulu, Muhasebe ve Denetim Bölümü’nde öğrenim gören öğrenciler oluşturmaktadır. Okula kayıtlı 188 öğrenci bulunmaktadır. Aktif olan öğrenci sayısı 162'dir. Anket okulda mevcut bulunan 141 öğrenciye uygulanmıştır. 141 öğrencinin tamamı tüm sorulara yanıt vermiştir. Anket uygulanan öğrenci sayısı aktif öğrenci sayısının \% 87'sini oluşturmaktadır. Yapılan anketlerin tamamı değerlendirilmiştir. 141 öğrencinin tamamı anketteki tüm sorulara yanıt vermiştir. Anket uygulamaya konulmadan önce, Bilecik Şeyh Edebali Üniversitesi Etik Kurulu’ndan gerekli izin ve onay alınmıştır.

Araştırmada "Tanımlayıcı (Betimsel) ve Bağıntısal Araştırma Modeli" kullanılmıştır. Veri toplama yöntemi olarak anket yöntemi kullanılmıştır. Anketin geçerliliğinin sınanması amacıyla literatür araştırması yapılmış, uzman görüşü alınmış ve anket uygulanmadan önce pilot çalışma yapılmıştır.

Verilerin analizi, SPSS (Statistical Package for the Social Sciences) paket programında yapılmıştır. Verilerin analizinde; frekans (sayı) ve yüzde tekniklerinden yararlanılmıştır. Değişkenler arasındaki farklılıkları ortaya koymak amacıyla Crosstabs testi uygulanmıştır. Öğrencilerin Muhasebe ve Denetim Bölümü'nü seçme sebepleri ve öğrencilerin muhasebe mesleği hakkındaki düşünceleri alınırken 3'lü Likert (3.Katılıyorum-2.Kararsızım-1.Katılmıyorum) ölçeği kullanılmıştır.

\section{Araştırma Bulguları}

\section{Demografik Dağılım}

Anketin uygulandığı öğrenci sayısı 141'dir. Öğrencilerin \% 64,5'ini kadın, \% 35,5'ini erkek öğrenciler oluşturmaktadır. Kadın öğrencilerin erkek öğrencilerden sayıca fazla olduğu görülmektedir (Tablo 1). 
Tablo 1. Cinsiyet Dağııımı

\begin{tabular}{ccc}
\hline & Sayı & \% \\
\hline Kadın & 91 & 64,5 \\
\hline Erkek & 50 & 35,5 \\
\hline Toplam & $\mathbf{1 4 1}$ & $\mathbf{1 0 0}$
\end{tabular}

Ankete katılan öğrencilerin sınıfları Tablo 2'de verilmiştir. Öğrencilerin \%31,2'si 1. sınıfta, \%24,1’i 2. sınıfta, \%22,7'si 3. sinıfta, \%22'si 4. sınıfta öğrenim görmektedir.

Tablo 2. Sınıf Dağılımı

\begin{tabular}{rcc}
\hline & Sayı & \% \\
\hline 1. Sınıf & 44 & 31,2 \\
\hline 2. Sınıf & 34 & 24,1 \\
\hline 3. Sınıf & 32 & 22,7 \\
\hline 4. Sınıf & 31 & 22,0 \\
\hline Toplam & 141 & 100 \\
\hline
\end{tabular}

Öğrencilerin ağırlıklı olarak Marmara Bölgesi’nden geldikleri görülmektedir. İkinci sırada Karadeniz Bölgesi yer almaktadır. Üçüncü sırada İç Anadolu Bölgesi yer almaktadır (Tablo 3).

Tablo 3. Öğrencilerin Ikamet Ettikleri Bölgelere Göre Dağılımı

\begin{tabular}{lrc}
\hline & Sayı & \% \\
\hline Marmara & 82 & 58,2 \\
\hline İc Anadolu & 18 & 12,8 \\
\hline Ege & 8 & 5,7 \\
\hline Karadeniz & 19 & 13,5 \\
\hline Akdeniz & 8 & 5,7 \\
\hline Doğu Anadolu & 4 & 2,8 \\
\hline Güney Doğu Anadolu & 2 & 1,4 \\
\hline Toplam & $\mathbf{1 4 1}$ & $\mathbf{1 0 0}$ \\
\hline
\end{tabular}

Öğrencilerin \% 62,41’i Ticaret Lisesi, \%19,15’i düz lise mezunudur. Öğrencilerin \%18,44’ü İmam Hatip Lisesi, Kız Meslek Lisesi, Mesleki Teknik Endüstri Lisesi’nden mezundur. (Tablo 4).

Tablo 4. Öğrencilerin Mezun Oldukları Lise

\begin{tabular}{lcc}
\hline Mezun Olunan Lise & Sayı & \% \\
\hline Ticaret Lisesi & 88 & 62,41 \\
\hline Düz Lise & 27 & 19,15 \\
\hline Diğer & 26 & 18,44 \\
\hline Toplam & $\mathbf{1 4 1}$ & $\mathbf{1 0 0}$ \\
\hline
\end{tabular}

Cinsiyete göre öğrencilerin mezun oldukları liseler Tablo 5'te verilmiştir. 
Tablo 5. Cinsiyete Göre Öğrencilerin Mezun Oldukları Lise

\begin{tabular}{|c|c|c|c|c|c|c|}
\hline \multirow{3}{*}{ Mezun Olunan Lise } & \multicolumn{4}{|c|}{ Cinsiyet } & \multirow{2}{*}{\multicolumn{2}{|c|}{ Toplam }} \\
\hline & \multicolumn{2}{|c|}{ Kadın } & \multicolumn{2}{|c|}{ Erkek } & & \\
\hline & Sayı & $\%$ & Sayı & $\%$ & Sayı & $\%$ \\
\hline Ticaret Lisesi & 54 & 38,30 & 34 & 24,11 & 88 & 62,41 \\
\hline Düz Lise & 20 & 14,18 & 7 & 4,97 & 27 & 19,15 \\
\hline Diğer & 17 & 12,06 & 9 & 6,38 & 26 & 18,44 \\
\hline Toplam & 91 & 64.54 & 50 & 35,46 & 141 & 100 \\
\hline
\end{tabular}

Ticaret lisesinden mezun 88 öğrencinin \% 61,36'sını kadın öğrenciler, \% 38,64’ünü erkek öğrenciler oluşturmaktadır.

Üniversite tercih sıralamasında, Muhasebe ve Denetim Bölümü'nün ticaret lisesi, düz lise ve diğer liselerden mezun öğrencilerin çoğunun ilk 5 tercihi içinde yer aldığı görülmektedir (Tablo 6).

Tablo 6. Mezun Olunan Liseye Göre Muhasebe ve Denetim Bölümünü Tercih Etme Sıraları

\begin{tabular}{|l|c|c|c|c|c|c|}
\hline \multirow{2}{*}{ Mezun Olunan Lise } & \multicolumn{6}{|c|}{ Muhasebe ve Denetim Bölümünü Tercih Etme Sıraları } \\
\cline { 2 - 7 } & $\mathbf{1 - 5}$ & $\mathbf{6 - 1 0}$ & $\mathbf{1 1 - 1 5}$ & $\mathbf{1 6 - 2 0}$ & $\mathbf{2 1}$ ve üstü & Toplam \\
\hline Ticaret Lisesi & 60 & 16 & 6 & 3 & 3 & 88 \\
\hline Düz Lise & 19 & 4 & 1 & 1 & 2 & 27 \\
\hline Diğer & 17 & 3 & 3 & 3 & 0 & 26 \\
\hline \multicolumn{1}{|c|}{ Toplam } & $\mathbf{9 6}$ & $\mathbf{2 3}$ & $\mathbf{1 0}$ & $\mathbf{7}$ & $\mathbf{5}$ & $\mathbf{1 4 1}$ \\
\hline
\end{tabular}

Öğrencilerin \% 46,1'i yüksek lisans yapmayı düşünmekte, \% 53,9'u yüksek lisans yapmayı düşünmemektedir.

\section{Öğrencilerin Muhasebe Mesleğini Seçme Sebepleri}

Muhasebe ve Denetim Bölümü'nü seçme sebepleri ile ilgili sorular sorulmuştur. Öğrencilerin \%63,8'i Muhasebe ve Denetim Bölümü'nü muhasebe mesleğinde iş imkanları fazla olduğunu için seçtiklerini belirtmişlerdir. Öğrencilerin \% 61,7'si üniversite sınavında alınan puanın bu bölümü seçmesinde etkili olduğunu düşünmektedir. Öğrencilerin \% 49,6's1 muhasebe ve denetim bölümünü itibarlı bir meslek olduğu için seçtiklerini belirtmişlerdir. Öğrencilerin \% 56's1 muhasebe ve denetim bölümünü seçmelerinde ticaret lisesinde okumalarının etkili olduğunu belirtmişlerdir (Tablo 7). 
Tablo 7. Öğrencilerin Muhasebe ve Denetim Bölümü'nü Seçme Sebepleri

\begin{tabular}{|l|c|c|c|c|c|c|c|}
\hline \multirow{2}{*}{} & \multicolumn{2}{|c|}{ Katılıyorum } & \multicolumn{2}{c|}{ Kararsızım } & \multicolumn{2}{c|}{ Katılmıyorum } & \multirow{2}{*}{ Ortalama } \\
\cline { 2 - 7 } & Sayı & $\%$ & Sayı & $\%$ & Sayı & $\%$ & \\
\hline $\begin{array}{l}\text { Muhasebe ve denetim bölümünü } \\
\text { itibarlı bir meslek olduğu için seçtim. }\end{array}$ & 70 & 49,6 & 43 & 30,5 & 28 & 19,9 & 2,29 \\
\hline $\begin{array}{l}\text { Muhasebe ve denetim bölümünü } \\
\text { muhasebe mesleğinde iş imkanlarının } \\
\text { fazla olduğunu düşündüğü için } \\
\text { seçtim. }\end{array}$ & 90 & 63,8 & 31 & 22,0 & 20 & 14,2 & 2,49 \\
\hline $\begin{array}{l}\text { Üniversite sınavından aldığım puan } \\
\text { muhasebe ve denetim bölümünü } \\
\text { seçmemde etkili oldu. }\end{array}$ & 87 & 61,7 & 22 & 15,6 & 32 & 22,7 & 2,30 \\
\hline $\begin{array}{l}\text { Muhasebe ve denetim bölümünü } \\
\text { seçmemde ticaret lisesinde okumam } \\
\text { etkili oldu. }\end{array}$ & 79 & 56,0 & 10 & 7,1 & 52 & 36,9 & 2,19 \\
\hline
\end{tabular}

3.Katılıyorum 2.Kararsızım 1.Katılmıyorum

Öğrencilere bu bölümü kendi istekleriyle seçip/seçmedikleri sorulmuştur. Öğrencilerin \% 72,3'ü Muhasebe ve Denetim Bölümü’nü kendi istekleriyle seçtiklerini belirtmişlerdir. Öğrencilerin \% 23,4'ü bölüme bilmeden geldiklerini belirtmişlerdir. Bu bölümü ailesinin isteğiyle seçenlerin yüzdesi \%12,8'dir. Öğrencilerin \% 14,9'u ailesinde muhasebecilerin olmasının bu bölümü seçmelerinde etkili olduğunu belirtmişlerdir (Tablo 8).

Tablo 8. Öğrencilerin Muhasebe ve Denetim Bölümü’nü Kendi İstekleriyle Seçip/Seçmedikleri

\begin{tabular}{|l|c|c|c|c|c|c|c|}
\hline & \multicolumn{2}{|c|}{ Katılıyorum } & \multicolumn{2}{c|}{ Kararsızım } & \multicolumn{2}{c|}{ Katılmıyorum } & \multirow{2}{*}{ Ortalama } \\
\cline { 2 - 9 } & Sayı & $\%$ & Sayı & $\%$ & Sayı & $\%$ & \\
\hline $\begin{array}{l}\text { Muhasebe ve denetim bölümünü kendi } \\
\text { isteğimle seçtim. }\end{array}$ & 102 & 72,3 & 25 & 17,7 & 14 & 9,9 & 2,62 \\
\hline $\begin{array}{l}\text { Muhasebe ve denetim bölümüne } \\
\text { bilmeden geldim. }\end{array}$ & 33 & 23,4 & 14 & 9,9 & 94 & 66,7 & 1,56 \\
\hline $\begin{array}{l}\text { Muhasebe ve denetim bölümünü } \\
\text { ailemin isteği ile seçtim. }\end{array}$ & 18 & 12,8 & 16 & 11,3 & 107 & 75,9 & 1,36 \\
\hline $\begin{array}{l}\text { Ailemde muhasebecilerin olması bu } \\
\text { bolümü seçmemde etkili oldu. }\end{array}$ & 21 & 14,9 & 8 & 5,7 & 112 & 79,4 & 1,35 \\
\hline
\end{tabular}

3.Katılıyorum 2.Kararsızım 1.Katılmıyorum

\section{Öğrencilerin Muhasebe Mesleği Hakkındaki Düşünceleri}

Öğrencilere muhasebe mesleği hakkındaki düşünceleri sorulmuştur. Öğrencilerin verdiği yanıtlar Tablo 9'da görülmektedir. Öğrencilerin \% 92,9'u muhasebe mesleğinde etik kurallara uyulması gerektiğini düşünmesine rağmen muhasebede mükellefin değil toplumun çıkarlarının önemli olduğunu düşünenlerin yüzdesi $(\%$ 58,9) daha azdır. Öğrencilerin \% 48,2'si muhasebe mesleği doğruluk ve dürüstlük gerektirdiği için bu meslekte çalışmak istediklerini belirtmişlerdir. Öğrencilerin \%14,9’u muhasebe mesleğinin içe dönük (asosyal) bir meslek olduğunu düşünmektedir. Öğrencilerin \% 27,7'si de bu konuda kararsızdır. 
Tablo 9. Öğrencilerin Muhasebe Mesleği Hakkındaki Düşünceleri

\begin{tabular}{|l|c|c|c|c|c|c|c|}
\hline & \multicolumn{2}{|c|}{ Katılıyorum } & \multicolumn{2}{c|}{ Kararsızım } & \multicolumn{2}{c|}{ Katılmı́rum } & Ortalama \\
\cline { 2 - 7 } & Sayı & $\%$ & Sayı & $\%$ & Sayı & $\%$ & \\
\hline $\begin{array}{l}\text { Muhasebe mesleği doğruluk dürüstlük } \\
\text { gerektiren bir meslek olduğu için bu } \\
\text { meslekte çalışmak istiyorum. }\end{array}$ & 68 & 48,2 & 48 & 34,0 & 25 & 17,7 & 2,30 \\
\hline $\begin{array}{l}\text { Muhasebe mesleğinin içe dönük (asosyal) } \\
\text { bir meslek olduğunu düşünüyorum. }\end{array}$ & 21 & 14,9 & 39 & 27,7 & 81 & 57,4 & 1,57 \\
\hline $\begin{array}{l}\text { Muhasebe mesleğinde etik kurallara } \\
\text { uyulması gerektiğini düşünüyorum. }\end{array}$ & 131 & 92,9 & 8 & 5,7 & 2 & 1,4 & 2,91 \\
\hline $\begin{array}{l}\text { Muhasebede mükellefin değil toplumun } \\
\text { çıkarlarının olduğunu } \\
\text { düşünüyorum. }\end{array}$ & 83 & 58,9 & 39 & 27,7 & 19 & 13,5 & 2,45 \\
\hline $\begin{array}{l}\text { Mali müşavirlik mesleğinin kadınlara } \\
\text { uygun bir meslek olmadığını } \\
\text { düşünüyorum. }\end{array}$ & 14 & 9,9 & 8 & 5,7 & 119 & 84,4 & 1,25 \\
\hline
\end{tabular}

\section{Katılıyorum 2.Kararsızım 1.Katılmıyorum}

Öğrencilerin \% 9,9’u mali müşavirlik mesleğinin kadınlara uygun bir meslek olmadığını düşünmektedir. Öğrencilerin \% 5,7'si kararsızdır. Öğrencilerin \% 84,4’ü bu görüşe katılmamaktadır. Bu görüşe katılmayan öğrencilerin \% 56 sı kadın, \% 28,4’ü erkek öğrencilerdir. (Tablo 10). Tablo 10. Mali Müşavirlik Mesleğinin Kadınlara Uygun Bir Meslek Olmadığını
Düşünenlerin Cinsiyete Göre Dağılımı

\begin{tabular}{|c|c|c|c|c|c|c|c|c|}
\hline \multirow{2}{*}{ Cinsiyet } & \multicolumn{6}{|c|}{ Mali müşavirlik mesleğinin kadınlara uygun bir meslek olmadığını } \\
düşünüyorum. \\
\cline { 2 - 9 } & \multicolumn{2}{|c|}{ Katılıyorum } & \multicolumn{2}{c|}{ Kararsızım } & \multicolumn{2}{c|}{ Katıımıyorum } & \multicolumn{2}{c|}{ Toplam } \\
\cline { 2 - 9 } & Sayı & $\%$ & Sayı & $\%$ & Sayı & $\%$ & Sayı & $\%$ \\
\hline Kadın & 9 & 6,4 & 3 & 2,1 & 79 & 56,0 & 91 & 64,54 \\
\hline Erkek & 5 & 3,5 & 5 & 3,6 & 40 & 28,4 & 50 & 35,46 \\
\hline Toplam & 14 & 9,9 & 8 & 5,7 & 119 & 84,4 & 141 & 100 \\
\hline
\end{tabular}

\section{Öğrencilerin Çalışmak İstedikleri Sektör ve Kariyer Planları}

Ankete katılan öğrencilerin \% 39’u kamu sektöründe, \% 34'ü özel sektörde, \%27'si serbest çalışmayı düşünmektedir (Tablo 11).

Tablo 11. Öğrencilerin Çalışmak Istedikleri Sektör

\begin{tabular}{ccc}
\hline & Sayı & \% \\
\hline Kamu & 55 & 39 \\
\hline Özel & 48 & 34 \\
\hline Serbest & 38 & 27 \\
\hline Toplam & $\mathbf{1 4 1}$ & $\mathbf{1 0 0}$ \\
\hline
\end{tabular}


Öğrencilerin çalışmak istediği sektörün cinsiyete göre dağılımı Tablo 12'de verilmiştir. Kamu sektöründe çalışmak isteyen 55 öğrencinin \% 65,5’i kadın, \%34,5’i erkek öğrencidir. Özel sektörde çalışmak isteyen 48 öğrencinin \% 68,8'i kadın, \%31,2'si erkek öğrencidir. Serbest çalışmak isteyen 38 öğrencinin \%57,9’u kadın, \% 42,1'i erkek öğrencidir.

Tablo 12. Öğrencilerin Çalışmak Istediği Sektörün Cinsiyete Göre Dağıımı

\begin{tabular}{|c|c|c|c|c|c|c|}
\hline \multirow{2}{*}{ Cinsiyet } & \multicolumn{4}{|c|}{ Hangi sektörde çalışmayı düşünüyorsunuz? } \\
\cline { 2 - 7 } & \multicolumn{2}{|c|}{ Kamu } & \multicolumn{2}{|c|}{ Özel } & \multicolumn{2}{c|}{ Serbest } \\
\cline { 2 - 7 } & Sayı & $\%$ & Sayı & $\%$ & Sayı & $\%$ \\
\hline Kadın & 36 & 65,5 & 33 & 68,8 & 22 & 57,9 \\
\hline Erkek & 19 & 34,5 & 15 & 31,2 & 16 & 42,1 \\
\hline Toplam & 55 & 100 & 48 & 100 & 38 & 100 \\
\hline
\end{tabular}

Kariyer planları sorulduğunda öğrencilerin \%37,6's1 mali müşavir olmak, \%17'si işletmelerin muhasebe departmanında çalışmak, \% 14,2'si denetim firmasında çalışmak, \% 12,1'i akademisyen olmak, \%7,1’i kendi işini kurmak istediklerini belirtmişlerdir. (Tablo 13).

Tablo 13. Öğrencilerin Kariyer Planları

\begin{tabular}{lcc}
\hline & Sayı & $\%$ \\
\hline Mali Müşavirlik & 53 & 37,6 \\
\hline $\begin{array}{l}\text { Işletmenin muhasebe departmanında } \\
\text { çalışmak }\end{array}$ & 24 & 17,0 \\
\hline Denetim firmasında çalışmak & 20 & 14,2 \\
\hline Akademisyenlik & 17 & 12,1 \\
\hline Kendi işimi kurmak & 10 & 7,1 \\
\hline Diğer & 17 & 12,1 \\
\hline Toplam & 141 & 100 \\
\hline
\end{tabular}

\section{Sonuc}

Muhasebe ve Denetim Bölümü’nde öğrenim gören 141 öğrencinin, profilini ve muhasebe mesleğine bakışlarını ortaya koymak amacıyla yapılan bu çalışmada kadın öğrencilerin erkek öğrencilerden sayıca fazla olduğu görülmektedir. Öğrencilerin ağıllıklı olarak Marmara, Karadeniz ve İç Anadolu bölgelerinden geldikleri görülmektedir.

Öğrencilerin çoğunluğu ticaret lisesinden mezundur. Muhasebe ve Denetim Bölümü, üniversite tercih sıralamasında öğrencilerin büyük çoğunluğunun ilk 5 tercihi içinde yer almaktadır. Öğrenciler, üniversite sınavında alınan puanın bu bölümü seçmelerinde etkili olduğunu düşünmektedirler. Öğrencilerin çoğu, bu bölümü kendi isteğiyle seçtiğini belirtmiştir.

Muhasebe mesleği doğruluk ve dürüstlük gerektirdiği için bu meslekte çalışmak istediklerini belirtmişlerdir. Muhasebe mesleğinin içe dönük (asosyal) bir meslek olmadığını düşünmektedirler. Öğrencilerin büyük çoğunluğu muhasebe mesleğinde etik kurallara uyulması gerektiğini düşünmesine rağmen muhasebede mükellefin değil toplumun çıkarlarının önemli olduğunu düşünen öğrencilerin 
sayısı daha azdır. Öğrencilerin çoğu mali müşavirlik mesleğinin kadınlara uygun bir meslek olduğunu düşünmektedir. Kadın öğrenciler bu görüşe daha çok katılmaktadır.

Kamu sektöründe ve özel sektörde çalışmak isteyenlerin sayısı birbirine yakındır. Kadın öğrenciler bu sektörlerde çalışmayı daha çok istemektedirler. Kariyer planları sorulduğunda öğrenciler mali müşavir olmak, işletmelerin muhasebe departmanında çalışmak, denetim firmasında çalışmak, akademisyen olmak ve kendi işini kurmak istediklerini belirtmişlerdir.

\section{Kaynakça}

Arsoy, Poroy Aylin, Tuba Bora ve Seval Selimoğlu (2014), "Muhasebe Eğitimindeki Bilgi, Beceri ve Eğitim Tekniklerinin Gerekliliklerine İlişkin Beklentiler: Türkiye'deki Akademisyenlere ve Meslek Mensuplarına Yönelik Bir Araştırma”, Uluslararası Yönetim İktisat ve İşletme Dergisi, Cilt 10, Sayı 23, s. 121-136.

Coşkun, Recai ve Remzi Altunışık, Engin Yıldırım (2004), Sosyal Bilimlerde Araştırma Yöntemleri: SPSS Uygulamall, Sakarya Yayıncilık.

Ergun, Halil ve Kudret Gül (2005), "Muhasebe Mesleği Etik Kuralları ve Bu Kuralların Meslek Mensuplarınca Algılanışı", Muhasebe ve Finansman Dergisi, Sayı 25, s. 143-154.

Eymen, U. Erman (2007), SPSS 15 Veri Analiz Yöntemleri, İstatistik Merkezi Yayın No: 1.

Kurnaz, Niyazi ve Yusuf Gümüş̧ (2010), "Muhasebe Bölümü Öğrencilerinin Muhasebe Mesleği İle İlgili Etik Dışı Davranışlara İlişkin Algı Analizi: Dumlupınar Üniversitesi Uygulamalı Bilimler Yüksekokulu Örneği”, Muhasebe ve Finansman Dergisi, Say1 46, Nisan, s. 157-174. 